\title{
Sarcoidosis severity and socioeconomic status
}

\author{
D.L. Rabin*, M.S.A. Richardson ${ }^{\star}$, S.R. Stein*, H. Yeager Jr"
}

Sarcoidosis severity and socioeconomic status. D.L. Rabin, M.S.A. Richardson, S.R. Stein, H. Yeager Jr. (C) ERS Journals Ltd 2001.

ABSTRACT: Several chronic diseases are more severe in persons who are Black, of low socioeconomic status (SES), and underinsured. The authors ask if this is true for sarcoidosis. Associations among sarcoidosis disease severity, SES, insurance coverage, and functional limitations were analysed.

Back and White sarcoidosis patients (n=110) of a municipal and university hospital sarcoidosis registry were interviewed by telephone. Data on disease severity were abstracted from patient charts.

Most patients reported good or excellent health by demographic characteristics. Low SES and no or public insurance were associated with worse health status and more severe dyspnoea. More advanced radiographic stage was associated with lower income, and forced vital capacity impairment with less education. Physical and social activity limitations due to physical and emotional disability were related to no or public insurance and lower income, but not education.

Sarcoidosis severity is associated with socioeconomic status and insurance indicators; no or public insurance and low income are associated with functional limitations. Sarcoidosis-associated limitations are substantial, emphasizing the social significance of sarcoidosis. Lack of private insurance may inhibit the use of medical care, contributing to disease severity and impairment.

Eur Respir J 2001; 18: 499-506.

\begin{abstract}
*Dept of Family Medicine, Division of Community Health Care Studies and ${ }^{\#}$ Dept of Medicine, Division of Pulmonary and Critical Care Medicine, Georgetown University School of Medicine, Washington, D.C. and the Division of Pulmonary Medicine, District of Columbia General Hospital, Washington, D.C., USA.
\end{abstract}

Correspondence: D.L. Rabin, Dept of Family Medicine, Georgetown University Medical Center, 3750 Reservoir Road, N.W., Washington, D.C. 20007, USA.

Fax: 12026877108

Keywords: Functional status

insurance coverage

sarcoidosis

socioeconomic status

work and activity limitations

Received: June 222000

Accepted after revision February 14 2001

This work was supported by a grant from the National Institute of Allergy and Infectious Diseases of the National Institutes of Health, Grant no. 1-RO3AI38937-01.
A previous study by YEAGER et al. [1], comparing Black sarcoidosis patients in a municipal and a private university hospital in one city, found that municipal hospital patients had more severe pulmonary disease. It was conjectured that patient socioeconomic characteristics limiting access to private care may account for the more severe disease seen at the municipal hospital. Furthermore, the socioeconomic characteristics of sarcoidosis patients could affect insurance coverage, contributing to sarcoidosis disease severity. Blacks are more disadvantaged than Whites in these characteristics. However, an ecological study of county-level geographic variation in sarcoidosis hospitalizations in South Carolina, USA showed that increased rates of disease in counties near the coastline could not be explained by socioeconomic status (SES), insurance coverage, or healthcare resources [2]. Three times as many Black as White sarcoidosis patients were below the poverty line, and, although household income explained more of the variation in sarcoidosis hospitalization among Blacks than Whites, neither had much explanatory power in analytical models.
Young [3] called for sociodemographic studies, particularly on the social and functional consequences of sarcoidosis, while Newman et al. [4] commented on the absence of SES information and disease severity in their disease review.

The present study examines the socioeconomic and insurance characteristics of Black and White municipal and private hospital sarcoidosis clinic patients, their relationship to severity, and the disease's functional and social significance.

Blacks are far more likely both to have sarcoidosis and severe sarcoidosis [5]. In 1997, Black poverty rates $(26.5 \%)$ were significantly higher than White poverty rates $(11 \%)$ [6]. Black households had the lowest median household income (US\$25,050) by race [7]. Black Americans are less educated than White Americans and are less likely to complete high school (20\% of Blacks compared to $10 \%$ of Whites). Furthermore, Blacks are more likely to be uninsured (55\% of Blacks compared to $27 \%$ of Whites) [8].

SES measures social opportunity and is an indicator of lifestyle, health behaviour, and access to insurance. 
Many adult chronic diseases show associations among disease severity, SES, and insurance coverage [9]. People of low SES have a greater risk of occurrence and increased severity of many diseases, including cardiovascular, respiratory diseases and cancer [10]. There is a strong, inverse relationship with income and health status indicators, particularly mortality, among those with a household incomes <US\$30,000 [11]. Education is inversely related to higher rates of risky health behaviour and lower levels of use of medical care. Less education correlates with obesity, smoking, and substance use [12]. Those with a family income $<$ US $\$ 25,000$ are six times as likely to have no insurance coverage compared to those with a family income $>$ US\$50,000 [13]. Health insurance affects healthcare service use. Among the uninsured, those with chronic conditions are less likely than those with acute conditions to seek care [14]. When uninsured individuals do seek care, disease severity is worse, and treatment costs and intensity are greater [9]. Uninsured individuals also use less preventive services [15].

The association between race and health status is complex because of confounding by measures of SES, attitudes, and insurance [16]. Because the disease is more prevalent in Blacks, and Blacks represent only $12.8 \%$ of the US population [17], SES factors related to sarcoidosis severity may be attributed to race rather than SES or insurance.

\section{Materials and methods}

\section{Identification of patients}

Adult patients (aged $\geqslant 18$ yrs) were identified and entered into a sarcoidosis registry through computerized hospital ambulatory billing records for sarcoidosis-related International Classification of Diseases, adapted codes at Georgetown University Medical Center (GUMC), a private university hospital. Additional patients were identified from sarcoidosis clinic records at DC General Hospital (DCGH), a municipal hospital. While GUMC serves a socioeconomically diverse population, more patients are White and insured. DCGH serves a predominant minority (mostly Black), low-income population.

Medical charts from patients seen at GUMC and DCGH from July 1, 1992-December 31, 1996 were abstracted using a Sarcoidosis Registry Form including sociodemographic, insurance, sarcoidosis laboratory and chest radiograph data, and clinical symptoms. Seventeen per cent of medical records were abstracted twice by different abstractors. Of the 20 records abstracted, there were four discrepancies, all errors of omission.

\section{Inclusion criteria}

The registry population included all patients, aged $\geqslant 18$ yrs, with confirmed or suspected sarcoidosis (based on clinical diagnosis, with or without tissue biopsy) seen at least once. Patients who were mentally incapacitated (mentally retarded or psychotic), incarcerated, or non-English speaking, were excluded from further study.

\section{Measures}

A standardized telephone questionnaire was developed and pretested. This Sarcoidosis Telephone Survey Form assessed current health status, SES and demographic characteristics, and insurance status. General health status was assessed using questions taken from the Health Status Questionnaire Short-Form 36 [18]. Quality of life was assessed using physical and social function questions from the Medical Outcomes Study Short-Form General Health Survey [19]. Data on use of services, education, income, and health insurance were obtained using National Health Interview Survey questions. Dyspnoea was assessed by the Modified Medical Research Dyspnoea Scale [20].

\section{Data analysis}

Most analyses consisted of descriptive statistics. Where applicable, data analyses included crosstabulations, using the nonparametric contingency coefficient, to determine the degree and significance of an association between several variables related to sociodemographic, health status, and medical services usage. The contingency coefficient, based on Chisquared, is a nonparametric test for use with nominal level variables, and expressed as a p-value significance level. p-Values $<0.05$ were considered statistically significant.

\section{Study population}

Of the 282 sarcoidosis registry patients, 63\% were from GUMC. Most patients $(78 \%)$ were seen at a pulmonary or sarcoidosis clinic. The remaining patients were seen at GUMC speciality clinics: Rheumatology $(5 \%)$, Ophthalmology $(14 \%)$, General Internal Medicine or Family Practice (2\%), and Dermatology $(1 \%)$.

\section{Telephone survey population comparisons}

Of the 282 registry patients, 256 were eligible for the phone survey. One-hundred and fifteen of these did not have a current identifiable phone number, leaving 141 eligible patients with an identifiable current phone; $22 \%$ refused participation, leaving a total interviewed population of 110 .

The interviewed, telephone-accessible, eligible registry patients were compared by demographic, insurance, or symptom characteristics (table 1). There were no significant differences for either comparison group for the 15 demographic, employment insurance, or sarcoidosis symptom characteristics; the interviewed and locatable groups were nearly identical, but fewer 
Table 1. - Comparison of eligible registry cases bv interview status by demographic and sarcoidosis characteristics

\begin{tabular}{|c|c|c|c|c|c|}
\hline \multirow[t]{2}{*}{ Characteristics } & \multicolumn{5}{|c|}{ Interview status } \\
\hline & Interviewed & All eligible & $\mathrm{p}$-value & All locatable & p-value \\
\hline Patients $\mathrm{n}$ & 110 & 256 & & 141 & \\
\hline \multicolumn{6}{|l|}{ Demographics } \\
\hline Mean age yrs & 46.0 & 43.8 & 0.992 & 45.7 & 0.896 \\
\hline Black & 72.7 & 78.1 & 0.321 & 73.0 & 0.955 \\
\hline Female & 75.5 & 67.6 & 0.132 & 75.2 & 0.960 \\
\hline Seen at GUMC & 73.6 & 65.6 & 0.132 & 74.5 & 0.881 \\
\hline Married & 31.8 & 26.2 & 0.269 & 32.6 & 0.892 \\
\hline Employed & 56.2 & 54.5 & 0.812 & 58.1 & 0.806 \\
\hline Uninsured & 6.7 & 9.2 & 0.489 & 6.2 & 0.875 \\
\hline More than one organ involved & 33.6 & 31.6 & 0.628 & 29.1 & 0.998 \\
\hline \multicolumn{6}{|l|}{ Sarcoidosis characteristics } \\
\hline Cough & 27.3 & 26.6 & 0.888 & 26.2 & 0.855 \\
\hline Chest pain & 10.9 & 10.2 & 0.829 & 10.6 & 0.945 \\
\hline Shortness of breath & 27.3 & 32.0 & 0.365 & 28.4 & 0.848 \\
\hline Weight loss & 4.5 & 5.1 & 0.829 & 4.3 & 0.991 \\
\hline Skin rash & 6.2 & 4.7 & 0.386 & 2.1 & 0.758 \\
\hline Loss of appetite & 2.7 & 2.7 & 0.997 & 2.1 & 0.758 \\
\hline Fever & 2.7 & 4.7 & 0.386 & 3.5 & 0.714 \\
\hline
\end{tabular}

Data are presented as percentages (\%) unless otherwise stated. GUMC: Georgetown University Medical Center.

males and DCGH patients were interviewed than represented in the group of eligible registry patients. When compared by hospital and clinic of origin, interviewed patients differed significantly, with fewer DCGH clinic patients. Interviewed patients had a mean age of $46 \mathrm{yrs}$ and were predominantly Black, female, seen at GUMC, and privately insured. The most common sarcoidosis symptoms were cough and shortness of breath, recorded for about one-quarter of the patients; other symptoms were uncommonly reported.

\section{Results}

\section{Interview group characteristics}

Few patients had less than a high school education (19\%). Household income was <US\$20,000 for $30 \%$, all of whom were Black, but $41 \%$ of patients had incomes $>$ US\$50,000. Twenty-seven per cent had no or public insurance (Medicaid); only $7 \%$ had no insurance. Black patients were significantly more likely to have less education, lower income, and no insurance. Most patients, however, had more than a high school education, private insurance (including Medicare), and incomes $>$ US\$20,000. Table 2 reports self-perceived general health status of sarcoidosis patients in two categories derived from a five-point scale: Excellent to Poor (where responses do not add up to $100 \%$ on any table, information was not available; percentages are for known responses). About $70 \%$ of patients reported being in excellent or good health, with no significant differences by demographic characteristics. Fair-to-poor general health status was significantly related to less education, income, and having no or public insurance.
Sarcoidosis severity and socioeconomic status insurance indicators

The relationship of sarcoidosis severity to SES and insurance status is shown in table 3. The interview ascertained subjective measures of sarcoidosis severity-related symptoms in the past month: dyspnoea, chest pain, cough, fever, weight loss, skin rash, uveitis

Table 2. - Self-assessed general health status by demographic and socioeconomic status (SES) characteristics

Characteristics

Self-assessed health status

Excellent/very Fair/poor p-value good/good

\begin{tabular}{llrl}
\hline $\begin{array}{l}\text { Demographics } \\
\text { Age }\end{array}$ & & & \\
$\quad \leqslant 48$ yrs & $42(72)$ & $16(28)$ & 0.782 \\
$\quad>48$ yrs & $35(70)$ & $15(30)$ & \\
Sex & $18(66)$ & $9(33)$ & 0.539 \\
M & $59(73)$ & $22(27)$ & \\
F & & & \\
Race & $57(68)$ & $27(32)$ & 0.139 \\
$\quad$ Black & $20(83)$ & $4(17)$ & \\
$\quad$ White & & & \\
SES and insurance status & & & \\
Education level & $71(77)$ & $21(23)$ & 0.001 \\
$\quad \quad$ High school & $71(77)$ & $21(23)$ & \\
$\quad>$ High school & & & \\
Income US\$ & $11(38)$ & $18(62)$ & $<0.001$ \\
$\quad$ 20000 & $26(77)$ & $8(24)$ & \\
$\quad$ 20000-49999 & $37(90)$ & $4(10)$ & \\
$\quad$ 50000 & & & \\
Insurance status & $10(34)$ & $19(66)$ & $<0.001$ \\
$\quad$ None or public & $67(85)$ & $12(15)$ & \\
$\quad$ Private & & & \\
\hline
\end{tabular}

Data are presented as $\mathrm{n}(\%)$ unless otherwise stated. $\mathrm{M}$ : male; F: female. 
Table 3. - Sarcoidosis severity by socioeconomic status and insurance status

\begin{tabular}{|c|c|c|c|c|c|c|c|}
\hline \multirow[t]{2}{*}{ Characteristics } & \multicolumn{2}{|c|}{ Education } & \multicolumn{3}{|c|}{ Income US\$ } & \multicolumn{2}{|c|}{ Insurance status } \\
\hline & $\begin{array}{l}<\text { High } \\
\text { school }\end{array}$ & $\begin{array}{l}\geqslant \text { High } \\
\text { school }\end{array}$ & $<20000$ & $20000-49999$ & $\geqslant 50000$ & $\begin{array}{l}\text { None or } \\
\text { public }\end{array}$ & Private \\
\hline \multicolumn{8}{|l|}{ Subjective health status } \\
\hline $\begin{array}{l}\text { Self-reported dyspnoea } \\
\text { p-value }\end{array}$ & & 0.007 & \multicolumn{3}{|c|}{0.002} & \multicolumn{2}{|c|}{0.006} \\
\hline None & $2(12)$ & $47(51)$ & $8(28)$ & $15(44)$ & $24(59)$ & $6(21)$ & $43(54)$ \\
\hline Mild-to-moderate & $7(44)$ & $30(33)$ & $8(28)$ & $14(41)$ & $14(34)$ & $11(38)$ & $26(33)$ \\
\hline Severe/very severe & $7(44)$ & $15(16)$ & $13(45)$ & $5(15)$ & $3(7)$ & $12(41)$ & $10(13)$ \\
\hline Number of sarcoidosis symptoms & & & & & & \multirow{2}{*}{\multicolumn{2}{|c|}{0.920}} \\
\hline p-value & \multicolumn{2}{|c|}{0.090} & \multicolumn{3}{|c|}{0.077} & & \\
\hline None & $0(0)$ & 17 (18) & $4(14)$ & $6(18)$ & $13(33)$ & $1(4)$ & $16(20)$ \\
\hline $1-3$ & $7(44)$ & $43(47)$ & $14(50)$ & $12(36)$ & $20(50)$ & $14(48)$ & $36(46)$ \\
\hline$\geqslant 4$ & $9(56)$ & $32(35)$ & $10(36)$ & $15(46)$ & $7(18)$ & $14(48)$ & $27(34)$ \\
\hline \multicolumn{8}{|l|}{ Objective health status } \\
\hline \multicolumn{8}{|l|}{$\begin{array}{l}\text { Number of doctor appointments } \\
\text { in past year }\end{array}$} \\
\hline p-value & \multicolumn{2}{|c|}{0.833} & \multicolumn{3}{|c|}{0.163} & \multicolumn{2}{|c|}{0.430} \\
\hline None & $4(25)$ & $30(33)$ & $8(33)$ & $6(21)$ & $17(45)$ & $6(21)$ & $28(35)$ \\
\hline $1-3$ & $5(31)$ & $26(28)$ & $4(17)$ & $11(38)$ & $9(24)$ & $8(28)$ & $23(29)$ \\
\hline$\geqslant 4$ & $7(44)$ & $36(39)$ & $12(50)$ & $12(41)$ & $12(32)$ & $15(52)$ & $28(35)$ \\
\hline \multicolumn{8}{|l|}{ Radiographic stage } \\
\hline p-value & \multicolumn{2}{|c|}{0.410} & \multicolumn{3}{|c|}{0.034} & \multicolumn{2}{|c|}{0.200} \\
\hline Stage 1 & $1(12)$ & $12(25)$ & $1(7)$ & $3(21)$ & $9(36)$ & $2(10)$ & $10(29)$ \\
\hline Stage 2 & $2(25)$ & $18(38)$ & $3(21)$ & $5(36)$ & $11(44)$ & $6(30)$ & $14(40)$ \\
\hline Stage 3 and 4 & $5(63)$ & $18(38)$ & $10(72)$ & $6(43)$ & $5(20)$ & $12(60)$ & $11(31)$ \\
\hline \multicolumn{8}{|l|}{ Pulmonary function tests FVC } \\
\hline p-value & \multicolumn{2}{|c|}{0.041} & \multicolumn{3}{|c|}{0.535} & \multicolumn{2}{|c|}{0.091} \\
\hline Normal & $6(60)$ & $34(72)$ & $7(54)$ & $10(77)$ & $22(79)$ & $8(53)$ & $32(76)$ \\
\hline Mild & $0(0)$ & $8(17)$ & $3(23)$ & $4(15)$ & $3(11)$ & $2(13)$ & $6(14)$ \\
\hline Moderate/severe & $4(40)$ & $5(11)$ & $3(23)$ & $1(8)$ & $3(11)$ & $5(33)$ & $4(10)$ \\
\hline \multicolumn{8}{|l|}{ FEV1 } \\
\hline p-value & \multicolumn{2}{|c|}{0.701} & & 0.411 & & & \\
\hline Normal & $6(60)$ & $31(57)$ & $7(50)$ & $10(63)$ & $19(61)$ & $10(59)$ & $27(57)$ \\
\hline Mild & $1(10)$ & $11(20)$ & $2(14)$ & $2(13)$ & $8(26)$ & $1(6)$ & $11(23)$ \\
\hline Moderate/severe & $3(30)$ & $12(22)$ & $5(36)$ & $4(25)$ & $4(13)$ & $6(35)$ & $9(19)$ \\
\hline$D \mathrm{~L}, \mathrm{CD}$ & & & & & & & \\
\hline p-value & & & & 0.710 & & & \\
\hline Normal & $4(33)$ & $20(36)$ & $5(28)$ & $5(29)$ & $13(45)$ & $5(22)$ & $19(42)$ \\
\hline Mild & $4(33)$ & $12(57)$ & $5(28)$ & $4(24)$ & $7(24)$ & $5(22)$ & $11(24)$ \\
\hline Moderate/severe & $4(33)$ & $24(43)$ & $8(44)$ & $8(47)$ & $9(31)$ & $13(57)$ & $15(33)$ \\
\hline
\end{tabular}

Data are presented as n (\%) unless otherwise stated. FVC: forced vital capacity; FEV1: forced expiratory volume in one second; $D$ L,CD: carbon monoxide diffusing capacity of the lung.

or other eye problems, and fatigue. Objective severity measures were derived from chart abstracts: radiographic stage of chest disease and pulmonary function tests.

Severity of dyspnoea was significantly associated with level of education, lower income, and having no or public insurance. While nearly half of patients reported no dyspnoea, this was more likely in higher SES and privately insured patients. The number of self-reported sarcoidosis-related symptoms was unrelated to education, income, or insurance status, but the highest income patients were more likely to report no symptoms or fewer symptoms, if symptomatic.

Some patients were identified in nonpulmonary speciality clinics and others were referred from outside the hospital; radiographic and pulmonary function data were available in about one-half of the patients. For those with radiographs, more extensive lung involvement was significantly associated with lower income but not with education and insurance. Patients with incomes $<$ US\$20,000 were 3.5 times as likely to have Stage 3-4 disease than patients with incomes $>$ US\$50,000. Patients with the highest incomes were more likely $(36 \%$ versus $7 \%$ ) to have Stage 1 disease than patients with the lowest incomes. Pulmonary function test results were, in general, not associated with differences by income or insurance, although those less educated were significantly more likely to have moderate or severe restriction in vital capacity (40\% versus $11 \%)$.

Table 4 reports sarcoidosis symptom change in the past year. Few patients reported disease worsening; only by race was there a significant change in a year, with more Black than White patients reporting worsening ( $15 \%$ versus $8 \%)$, and more Black patients reporting improvement (45\% versus $17 \%)$. No other indicator was associated with changed sarcoidosis status. 
Table 4. - Self-assessed 1-yr change in sarcoidosis health status by demogaraphic, socioeconomic status (SES), and insurance status

\begin{tabular}{|c|c|c|c|c|}
\hline \multirow[t]{2}{*}{ Characteristics } & \multicolumn{4}{|c|}{ Self-assessed health status } \\
\hline & Better & $\begin{array}{l}\text { About the } \\
\text { same }\end{array}$ & Worse & $\mathrm{p}$-value \\
\hline \multicolumn{5}{|l|}{ Demographics } \\
\hline \multicolumn{5}{|l|}{ Age yrs } \\
\hline$\leqslant 48$ & $22(42)$ & $25(47)$ & $6(11)$ & \multirow[t]{2}{*}{0.658} \\
\hline$>48$ & $15(33)$ & $23(51)$ & 7 (16) & \\
\hline \multicolumn{5}{|l|}{ Sex } \\
\hline M & $11(50)$ & $8(36)$ & $3(14)$ & \multirow[t]{2}{*}{0.359} \\
\hline $\mathrm{F}$ & $26(34)$ & $40(53)$ & $10(13)$ & \\
\hline \multicolumn{5}{|l|}{ Race } \\
\hline Black & $33(45)$ & $30(40)$ & $11(15)$ & \multirow[t]{2}{*}{0.013} \\
\hline White & $4(17)$ & $18(75)$ & $2(8)$ & \\
\hline \multicolumn{5}{|l|}{$\begin{array}{l}\text { SES and insurance } \\
\text { status }\end{array}$} \\
\hline \multicolumn{5}{|l|}{ Education level } \\
\hline$<$ High school & $6(43)$ & $6(43)$ & $2(14)$ & \multirow[t]{2}{*}{0.882} \\
\hline$\geqslant$ High school & $31(37)$ & $42(50)$ & $11(13)$ & \\
\hline \multicolumn{5}{|l|}{ Income US\$ } \\
\hline$<20000$ & $9(60)$ & $3(20)$ & $3(20)$ & \multirow[t]{3}{*}{0.106} \\
\hline $20000-49999$ & $12(39)$ & $15(48)$ & $4(13)$ & \\
\hline$\geqslant 50000$ & $12(31)$ & $24(62)$ & $3(8)$ & \\
\hline \multicolumn{5}{|l|}{ Insurance status } \\
\hline None or public & $10(40)$ & $9(36)$ & $6(24)$ & \multirow[t]{2}{*}{0.128} \\
\hline Private & $27(37)$ & $39(53)$ & $7(10)$ & \\
\hline
\end{tabular}

Data are presented as $\mathrm{n}(\%)$ unless otherwise stated. M: male; F: female.

\section{Work and activity limitations due to sarcoidosis}

Patients were asked about activity limitations in the past 4 weeks due to physical or emotional disability (such as feeling depressed or anxious) in number, amount, and kind of activities. In addition, they were asked if their physical or emotional state had affected social activities.

There were consistent, significant associations among income, insurance status, and the amount and kind of limitations in the activities sarcoidosis patients could do because of both physical and emotional disability (table 5). In contrast, education was inconsistently and marginally associated with activity limitations. Lower income patients were more likely to be limited in both the amount and kind of activity they could do because of physical or emotional health. Insurance was associated with each type of work limitation due to physical disability and to amount and kind due to emotional disability, with those not or publicly insured consistently worse off. Respondents reported limitations in normal social activities due to sarcoidosis on a five-point scale ranging from "not at all" to "extremely", with the poorest and less well insured respondents significantly more likely to report social activities.

\section{Discussion}

Many sarcoidosis studies are of patients of a single hospital clinic. The present study includes sarcoidosis patients of multiple clinics in a municipal and a private university hospital, representing a broader spectrum of sarcoidosis patients by SES and presentation than seen in any one hospital. Survey patients had similar demographic characteristics to other US sarcoidosis populations studied: young adults, predominantly Black and female. Even with inclusion of municipal hospital patients, nearly all surveyed patients were insured, although many, particularly municipal hospital patients, had public insurance (Medicaid, i.e. welfare insurance) rather than private insurance or Medicare, which provides similar coverage to private insurance.

Even with sarcoidosis, most patients reported being in good-to-excellent general health and having few sarcoidosis symptoms. It was largely those with symptomatic sarcoidosis who reported poorer health, as might be expected in a young adult population that do not yet manifest the chronic diseases of aging. Objective data on disease severity were more often available for pulmonary clinic patients; by chest radiograph, most patients had radiologic Stage 2 or worse disease. Most patients perceived their disease as stable or improved, few as having progressed. Indeed, while general health status was strongly related to SES and insurance, there was no relationship with disease progression in a year, implying that, once in care, disease progression is unaffected by these factors. Blacks were more likely to report change, particularly improvement.

The reason that more Blacks than Whites reported improvement is unclear. As a group, the former had more severe disease and were more likely to be placed on therapy. The authors speculate that those on therapy would have had a greater sense of having improved in the past year. Whites, having less severe disease, are less likely to be on therapy and, therefore, less likely to have perceived improvement.

Three-quarters of the study patients were Black, with similar age and sex characteristics as White patients. Blacks were more likely to have less education, to be of lower income, and to have no or public insurance; however, most Blacks had more than a high school education and household incomes $>\mathrm{US} \$ 20,000 \cdot \mathrm{yr}^{-1}$ [21]. Analysis shows a strong association between SES and disease severity, so race confounds both SES and disease severity [22].

SES indicators and insurance were strongly associated with general health status of sarcoidosis patients. Regarding sarcoidosis severity, there were strong associations with severity of dyspnoea and SES and insurance, but no association with the number of sarcoidosis symptoms, a crude measure of disease extent. More objectively, radiograph severity was associated with income, and forced vital capacity with less education; there were no consistent associations for other pulmonary function test (PFT) measures, SES, or insurance. However, there were fewer observations with these objective measures ( 55 for the PFTs and 56 for the radiographs, as compared to nearly twice that number for self-perceived disease status), which could obscure some associations.

Data on work, activity, and social limitations ascribed to sarcoidosis were available for nearly all 
Table 5. - Work and activity limitations of sarcoidosis patients due to physical and emotional disability by socioeconomic status (SES) and insurance status

\begin{tabular}{|c|c|c|c|c|c|c|c|}
\hline \multirow[t]{2}{*}{ Functional limitation } & \multicolumn{2}{|c|}{ Education } & \multicolumn{3}{|c|}{ Income US\$ } & \multicolumn{2}{|c|}{ Insurance status } \\
\hline & $<$ High school & $\geqslant$ High school & $<20,000$ & $20,000-49,999$ & $\geqslant 50,000$ & None or publi & Private \\
\hline \multicolumn{8}{|c|}{$\begin{array}{l}\text { Activity limitations due to } \\
\text { physical disability }\end{array}$} \\
\hline \multicolumn{8}{|l|}{ Number } \\
\hline $\begin{array}{l}\mathrm{p} \text {-value } \\
\text { None }\end{array}$ & $47(7)$ & 0.504 & $10(36)$ & $\begin{array}{r}0.0 / 6 \\
18(53)\end{array}$ & $23(58)$ & \multicolumn{2}{|c|}{0.005} \\
\hline Some & $2(13)$ & $20(22)$ & $5(18)$ & $6(18)$ & $11(28)$ & $8(29)$ & $14(18)$ \\
\hline Many & $6(40)$ & $24(26)$ & $13(46)$ & $10(29)$ & $6(15)$ & $13(46)$ & $17(22)$ \\
\hline Amount & & & & & & & \\
\hline p-value & \multicolumn{2}{|c|}{0.126} & \multicolumn{3}{|c|}{0.215} & \multicolumn{2}{|c|}{0.026} \\
\hline Limited & $7(47)$ & $25(27)$ & $12(43)$ & $8(24)$ & $32(78)$ & $13(46)$ & $19(24)$ \\
\hline Not limited & $8(53)$ & $67(73)$ & $16(57)$ & $26(77)$ & $9(22)$ & $15(54)$ & $60(76)$ \\
\hline Kind & & & & & & \multirow{2}{*}{\multicolumn{2}{|c|}{0.003}} \\
\hline $\mathrm{p}$-value & \multicolumn{2}{|c|}{0.169} & \multicolumn{3}{|c|}{0.022} & & \\
\hline Limited & $8(53)$ & $32(35)$ & $16(57)$ & $13(38)$ & 30 (76) & $17(61)$ & $23(29)$ \\
\hline Not limited & $7(47)$ & $60(65)$ & $12(43)$ & $21(62)$ & $10(24)$ & $11(39)$ & $56(71)$ \\
\hline \multicolumn{8}{|c|}{$\begin{array}{l}\text { Activity limitations due to } \\
\text { emotional disability }\end{array}$} \\
\hline \multicolumn{8}{|c|}{ Number } \\
\hline p-value & \multicolumn{2}{|c|}{0.561} & \multicolumn{3}{|c|}{0.20} & \multicolumn{2}{|c|}{0.144} \\
\hline None & $9(60)$ & $51(58)$ & $11(39)$ & $16(50)$ & $30(77)$ & $11(39)$ & $49(65)$ \\
\hline Some & $2(13)$ & $9(22)$ & $8(29)$ & $6(19)$ & 7 (18) & $7(25)$ & $14(19)$ \\
\hline Many & $4(27)$ & $18(20)$ & $9(32)$ & $10(31)$ & $2(5)$ & $10(36)$ & $12(16)$ \\
\hline Amount & & & & & & \multirow{2}{*}{\multicolumn{2}{|c|}{0.043}} \\
\hline p-value & \multicolumn{2}{|c|}{0.890} & \multicolumn{3}{|c|}{0.005} & & \\
\hline Limited & $4(27)$ & $25(28)$ & $12(43)$ & $12(37)$ & $4(10)$ & $12(43)$ & $17(28)$ \\
\hline Not limited & $11(73)$ & $63(72)$ & $16(57)$ & $20(63)$ & $35(90)$ & $16(57)$ & $58(77)$ \\
\hline \multicolumn{8}{|l|}{ Kind } \\
\hline $\mathrm{p}$-value & \multicolumn{2}{|c|}{0.067} & \multicolumn{3}{|c|}{0.001} & \multicolumn{2}{|c|}{0.009} \\
\hline Limited & $6(40)$ & 17 (19) & $11(39)$ & $10(30)$ & $1(2)$ & $11(39)$ & $65(84)$ \\
\hline Not limited & $9(60)$ & $73(81)$ & $17(61)$ & $23(70)$ & $39(98)$ & $17(61)$ & $12(16)$ \\
\hline \multicolumn{8}{|c|}{$\begin{array}{l}\text { Social limitations due to } \\
\text { physical or emotional } \\
\text { disability }\end{array}$} \\
\hline p-value & & & & 0.056 & & 0.0 & \\
\hline None & $9(60)$ & $51(58)$ & $16(57)$ & $23(68)$ & $30(77)$ & $11(39)$ & $49(65)$ \\
\hline Some & $2(13)$ & $19(22)$ & $6(21)$ & $6(18)$ & $7(18)$ & $7(25)$ & $14(19)$ \\
\hline Many & $4(27)$ & $18(20)$ & $6(21)$ & $5(15)$ & $2(5)$ & $10(36)$ & $12(16)$ \\
\hline
\end{tabular}

Data are presented as n (\%) unless otherwise stated.

patients. Having no or public insurance and lower income was consistently related with activity limitations due to physical or emotional disability and social limitations, indicators of the functional consequences of disease severity.

\section{Implications}

The findings have several implications. Those with no or public insurance were more likely to have activity limitations, to report limitations in both kind and amount of activity, and to report dyspnoea. Pulmonary impairment signified by dyspnoea could compromise employability and access to work-associated private insurance, particularly for manual workers. Sarcoidosis patients with functional impairment and reduced income could lose insurance or become eligible for Medicaid, public welfare insurance available for those with medical need. The poor may delay medical care or not receive Medicaid until impaired.
Diagnosis may occur when disease is more advanced. Not all physicians will see Medicaid patients, thus restricting access to care. SES and insurance are not associated with worsening of sarcoidosis health status in a year, suggesting that sarcoidosis control is possible despite insurance and income restrictions. Consistent with that, there were no differences in physician visits or medication use by sarcoidosis severity. Associations of income and insurance with disease severity and consequent limitations may be mediated through delayed presentation of diagnosis and care. Delayed presentation may lead to greater physical and social impairment.

The functional impairment and possible financial consequences of sarcoidosis have not previously been documented. However, a study of sarcoidosis patients' quality of life showed fatigue and loss of energy to be major aspects of the disease for those who were symptomatic [23]. Sarcoidosis patients, particularly those fatigued, were also more likely to have depressive symptoms but not psychologically 
impaired health. Documentation of physical and social impairment for sarcoidosis patients adds to the significance of this disease. As sarcoidosis is a disease of young adulthood, those with impairment, particularly pulmonary impairment, are affected at a time when impairment could restrict household income when income needs are highest. The USA has recently revised its welfare system, decreasing the time people can remain on welfare. This change may particularly compromise young adults impaired by diseases such as sarcoidosis. Public and private work retirement systems depend upon years of work and income; disease effects may have lifelong consequences. Furthermore, sarcoidosis is not classified as an occupationally-related disease, so affected adults are not eligible for worker's compensation.

The confounding of race by SES measures is particularly complex for sarcoidosis, as there may be a genetic basis for sarcoidosis among some Blacks [21], but if SES and insurance affect disease severity, these are factors amenable to social policy, unlike race [22].

Confirmation and elaboration of this study's findings in a study on a larger population of Black and White patients seen at the same stage of disease is desirable. Such a study would identify the relative significance of race, SES, and insurance in disease severity at presentation and over time. This may be accomplished by analysis of the findings of A Case Control Etiology of Sarcoidosis Study (ACCESS) [24], in which 718 newly diagnosed patients were identified at the time of disease presentation and followed for 2 yrs.

While sarcoidosis is uncommon, it may be more significant in its consequences than many more common disorders. The aetiology of the disease remains unknown; there is no curative therapy. Because of its age of onset and form of disability, the activities of young adults (child rearing and work) are particularly compromised. The significance of many diseases is measured by mortality, an uncommon consequence of sarcoidosis, but measures of the functional and social consequences of diseases and time of onset are less dramatic, but important health measures [25]. These findings suggest that better understanding of the aetiology and treatment of sarcoidosis is a worthy health investment.

Acknowledgements. The authors gratefully acknowledge the assistance of J.K. French, E Centola, D.C. Arthur and R. Klau for development and preparation of this manuscript.

\section{References}

1. Yeager H, Rabin DL, Stein SR, Richardson MSA. Pulmonary sarcoidosis: Comparison of patients at a university and a municipal hospital. J Natl Med Assoc 1999; 91: 322-327.

2. Kajdasz DK, Judson MA, Mohr LC, Lackland DT. Geographic variation in sarcoidosis in South Carolina:
Its relation to socioeconomic status and health care indicators. Am J Epidemiol 1999; 150: 271-278.

3. Young R. Are sociodemographic factors important in sarcoidosis? J Natl Medical Assoc 1999; 91: 327-328.

4. Newman LS, Rose CS, Maier LA. Sarcoidosis. N Engl J Med 1997; 336: 1224-1234.

5. Hunninghake GW, Costabel U, Ando M, et al. ATS/ ERS/WASOG, Statement on sarcoidosis. Sarcoidosis Vasc Diffuse Lung Dis 1999; 16: 149-173.

6. Dalaker J, Naifeh M. Poverty in the United States: 1997. US Bureau of the Census, Current Population Reports. Washington, D.C., US Government Printing Office, 1998; pp. 60-201.

7. US Bureau of the Census. Money income in the United States: 1997. Census Bureau Current Population Reports. Washington, D.C., US Government Printing Office, 1998; pp. 60-200.

8. US National Center for Health Statistics. Health, United States, 1998, with socioeconomic status and health chartbook. Hyattsville, MD., US National Center for Health Statistics, 1998.

9. Anonymous. American College of Physicians-American Society of Internal Medicine. Decision 2000 campaign: No health insurance? It's enough to make you sick - Scientific research linking the lack of health coverage to poor health. Philadelphia, American College of Physicians - American Society of Internal Medicine, 1999.

10. Adler NE, Boyce T, Chesney MA, et al. Socioeconomic status and health. Am Psychol 1994; 49: 1524.

11. McDonough P, Duncan GJ, Williams D, House J. Income dynamics and adult mortality in the United States, 1972 through 1989. Am J Public Health 1997; 87: 1476-1483.

12. US Centers for Disease Control and Prevention. Prevalence of selected risk factors for chronic disease by education level in racial/ethnic populations - United States, 1991-1992. MMWR Morb Mortal Wkly Rep 1994; 43: 834-899.

13. US Bureau of the Census. Health insurance coverage, 1998. US Census Bureau Current Population Reports. Washington, D.C., US Government Printing Office, 1999; pp. 60-208.

14. Weinick RM, Zuvekas SH, Drilea SK. Access to health care - Sources and barriers, 1996. Medical Expenditure Panel Survey (MEPS) Research Findings No. 3. Rockville, MD, US. Agency for Health Care Research and Quality, 1997. Agency for Health Care Policy and Research Publication No. 98-0001.

15. Faulkner LA, Schauffler HH. The effect of health insurance coverage on the appropriate use of recommended clinical preventive services. Am J of Prev Med 1997; 13: 453-458.

16. Williams DR, Lavizzo-Mourey R, Warren RC. The concept of race and health status in America. Public Health Rep 1994; 109: 26-41.

17. DeBarros K, Bennett C. The Black population in the United States, March, 1997, Update. US Census Bureau Current Population Reports. Washington, D.C., US Government Printing Office, 1997; pp. 20 508

18. Ware JE Jr, Sherbone CD. The MOS 36-item shortform health survey (SF-36): I. Conceptual Framework and Item Selection. Med Care 1992; 30: 473-483.

19. Tarlov AV, Ware JE Jr, Greenfield S, Nelson EC, Perrin E, Zubkoff M. The medical outcomes study. 
An application of methods for monitoring the results of medical care. JAMA 1989; 262: 925-930.

20. Mahler DA, Wells CK. Evaluation of clinical methods for rating dyspnoea. Chest 1988; 93: 580-586.

21. Rybicki BA, Major M, Popovich J Jr, Maliarik MJ, Ianuzzi MC. Racial differences in sarcoidosis incidence: A 5-year study in a health maintenance organization. Am J Epidemiol 1997; 145: 234-241.

22. Stolley PD. Race in epidemiology. Int J H Serv 1999; 29: 905-909.

23. Weirnsberger RM, de Vries J, Breteler MH, van Heck
GL, Wouters EF, Drent M. Evaluation of quality of life in sarcoidosis patients. Respiratory Medicine 1998; 92: $750-756$.

24. A Case Control Etiology of Sarcoidosis Study (ACCESS) Research Group. Design of a case control etiologic study of sarcoidosis (ACCESS). $J$ Clin Epidemiol 1999; 52: 1173-1186.

25. Murray CJ, Lopez AD. The incremental effect of age-weighting on YLLs, YLDs and DALYs: A response. Bull World Health Organ 1996; 7: 445446. 